\title{
Aerosol light-scattering enhancement due to water uptake during the TCAP campaign
}

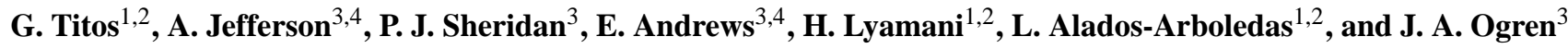 \\ ${ }^{1}$ Instituto Interuniversitario de Investigación del Sistema Tierra en Andalucía, IISTA-CEAMA, Universidad de Granada, \\ Junta de Andalucía, Granada, 18006, Spain \\ ${ }^{2}$ Department of Applied Physic, University of Granada, Granada, 18071, Spain \\ ${ }^{3}$ Earth System Research Laboratory, National Oceanic and Atmospheric Administration, Boulder, CO, 80305, USA \\ ${ }^{4}$ Cooperative Institute for Research in Environmental Sciences, University of Colorado, Boulder, CO, 80305, USA
}

Correspondence to: G. Titos (gtitos@ugr.es)

Received: 17 January 2014 - Published in Atmos. Chem. Phys. Discuss.: 5 February 2014

Revised: 20 May 2014 - Accepted: 5 June 2014 - Published: 10 July 2014

\begin{abstract}
Aerosol optical properties were measured by the DOE/ARM (US Department of Energy Atmospheric Radiation Measurements) Program Mobile Facility during the Two-Column Aerosol Project (TCAP) campaign deployed at Cape Cod, Massachusetts, for a 1-year period (from summer 2012 to summer 2013). Measured optical properties included aerosol light-absorption coefficient $\left(\sigma_{\mathrm{ap}}\right)$ at low relative humidity (RH) and aerosol light-scattering coefficient $\left(\sigma_{\mathrm{sp}}\right)$ at low and at $\mathrm{RH}$ values varying from 30 to $85 \%$, approximately. Calculated variables included the single scattering albedo (SSA), the scattering Ångström exponent (SAE) and the scattering enhancement factor $(f(\mathrm{RH}))$. Over the period of measurement, $f(\mathrm{RH}=80 \%)$ had a mean value of $1.9 \pm 0.3$ and $1.8 \pm 0.4$ in the $\mathrm{PM}_{10}$ and $\mathrm{PM}_{1}$ fractions, respectively. Higher $f(\mathrm{RH}=80 \%)$ values were observed for wind directions from 0 to $180^{\circ}$ (marine sector) together with high SSA and low SAE values. The wind sector from 225 to $315^{\circ}$ was identified as an anthropogenically influenced sector, and it was characterized by smaller, darker and less hygroscopic aerosols. For the marine sector, $f(\mathrm{RH}=80 \%)$ was 2.2 compared with a value of 1.8 obtained for the anthropogenically influenced sector. The air-mass backward trajectory analysis agreed well with the wind sector analysis. It shows low cluster to cluster variability except for air masses coming from the Atlantic Ocean that showed higher hygroscopicity. Knowledge of the effect of RH on aerosol optical properties is of great importance for climate forcing calculations and for comparison of in situ measurements with satellite and remote sensing retrievals. In this sense, predic-
\end{abstract}

tive capability of $f(\mathrm{RH})$ for use in climate models would be enhanced if other aerosol parameters could be used as proxies to estimate hygroscopic growth. Toward this goal, we propose an exponential equation that successfully estimates aerosol hygroscopicity as a function of SSA at Cape Cod. Further work is needed to determine if the equation obtained is valid in other environments.

\section{Introduction}

Earth's atmosphere plays an important role in the planetary energy budget through different processes that shape Earth's climate. Changes in its composition, even in the less abundant components, like aerosols, can drive climate changes. Aerosol particles actively scatter and absorb radiation as well as change the microphysical properties of clouds. An important factor that can modify the role of aerosols in the global energy budget is relative humidity (RH). Aerosol particles can take up water, become larger in size than their dry equivalents and, hence, scatter more light. Wet particles may also have different refractive indices and angular scattering properties than their dry counterparts. Continuous measurements of aerosol properties are typically performed under dry conditions $(\mathrm{RH}<40 \%)$ as recommended by international networks such as ACTRIS (Aerosols, Clouds, and Trace gases Research InfraStructure Network) or GAW (Global Atmosphere Watch; WMO/GAW, 2003). These measurements at low RH can differ from what would be observed at ambient 
conditions and thus difficult to relate to observations of the radiative energy budget. Therefore, knowledge of the scattering enhancement due to water uptake is of great importance in order to transform dry measurements into more relevant ambient measurements, especially when comparing in situ with remote sensing measurements (e.g., Zieger et al., 2011, 2012; Esteve et al., 2012; Shinozuka et al., 2013) or for satellite retrievals (e.g., Wang and Martin, 2007).

The effect of RH on the aerosol light-scattering coefficient can be determined by means of a tandem nephelometer system (Covert et al., 1972; Fierz-Schmidhauser et al., 2010a, and references therein). Typically, one nephelometer measures at a reference RH $(<40 \%)$ while the other nephelometer measures at a higher RH. The combination of both measurements allows determining the scattering enhancement factor, $f(\mathrm{RH})$, defined as the ratio between the scattering coefficient at high RH and the scattering coefficient at dry conditions. When these measurements are performed by scanning the higher $\mathrm{RH}$ over a range of values instead of at constant $\mathrm{RH}$, the evaluation of $f(\mathrm{RH})$ as a function of $\mathrm{RH}$ is possible. Different equations have been used to fit $f(\mathrm{RH})$ vs. RH. The most widely used equation is a two-parameter, power-law fit (e.g., Hänel and Zankl, 1979; Clarke et al., 2002). This equation uses a fit parameter $\gamma$ to describe the humidity dependence of $f(\mathrm{RH})$ for the entire $\mathrm{RH}$ range. The use of $\gamma$ allows comparing measurements taken at different RH values. Carrico et al. (2003) describe several other fitting techniques as well, applied to different RH ranges.

Many studies have been published assessing the impact of RH on the aerosol light-scattering coefficient for different aerosol types such as urban (Yan et al., 2009), freetroposphere (Fierz-Schmidhauser et al., 2010b), continental (e.g., Sheridan et al., 2001; Pan et al., 2009) and marine aerosols (e.g., McInnes et al., 1998; Fierz-Schmidhauser et al., 2010c). Much of the recent research was performed in central European sites (Zieger et al., 2013) and was focused on short measurement campaigns of 1-4 months duration. While there are a fair number of $f(\mathrm{RH})$ ground-based studies on a variety of aerosol types, very few of them have provided information on the aerosol scattering enhancement of fine mode aerosols; although some exceptions can be found in the literature (e. g., McInnes et al., 1998; Koloutsou-Vakakis et al., 2001; Sheridan et al., 2001; Carrico et al., 2003; FierzSchmidhauser et al., 2010a).

In this work, aerosol optical properties in two size ranges $\left(D_{\mathrm{p}}<1 \mu \mathrm{m}\right.$ and $\left.D_{\mathrm{p}}<10 \mu \mathrm{m}\right)$ were measured over a 1 -year period at Cape Cod (Massachusetts, USA) during the TwoColumn Aerosol Project (TCAP) campaign. Information concerning aerosol hygroscopicity is available for 7 months of the campaign. The main goals of this work are to characterize the hygroscopic scattering enhancement during the TCAP campaign and to explore the different situations and factors that led to changes in the hygroscopicity, as well as to explore the use of dry optical properties as proxies to estimate the hygroscopic enhancement.

\section{Experimental site and instrumentation}

\subsection{Site description}

The measurements presented in this study were conducted by the DOE/ARM (US Department of Energy Atmospheric Radiation Measurements) Program Mobile Facility (Miller and Slingo, 2007; Mather and Voyles, 2013) during the TCAP campaign (Kassianov et al., 2013) deployed at Cape Cod, Massachusetts. Cape Cod is a peninsula jutting out into the Atlantic Ocean in the easternmost portion of the state of Massachusetts, in the northeastern United States. The deployment was located in the northeastern part of the cape $\left(41^{\circ} 59^{\prime} 36^{\prime \prime} \mathrm{N}, 70^{\circ} 03^{\prime} 01^{\prime \prime} \mathrm{W}, 20 \mathrm{~m}\right.$ a.s.l.), inside the Cape Cod National Seashore, and relatively close to large urban agglomerations such as Providence and Boston. Thus, due to its location, the site is subject to both clean and polluted conditions. The campaign started in the summer of 2012 and lasted until the summer of 2013; however, due to problems with the humidifier system, measurements of the hygroscopic enhancement are only available for approximately half of the campaign (from late September to late October 2012 and then from January to mid June 2013).

\subsection{Instrumentation}

Air sampling for all the instrumentation used in this study was obtained from the top of a $10 \mathrm{~m}$ high sampling stack of $20.3 \mathrm{~cm}$ in diameter. Airflow through this main stack is about $800 \mathrm{~L} \mathrm{~min}^{-1}$. From this flow, $150 \mathrm{~min}^{-1}$ flow through a $5.1 \mathrm{~cm}$ diameter stainless steel pipe in the center of this larger flow that then is divided into five $30 \mathrm{~min}^{-1}$ sample lines. One of these sample lines goes to the aerosol observing system (AOS) instruments and the other four spare sample lines go out through a blower. A more detailed description of the sampling system can be found in Jefferson (2011).

The experimental setup consists of two integrating nephelometers (TSI, model 3563) operated in series and separated by a humidifier system. Since no active drying of the aerosol sample is performed after humidification only the lower branch of the hysteresis curve can be captured with this setup. The integrating nephelometer (TSI, model 3563) measures aerosol light-scattering $\left(\sigma_{\mathrm{sp}}\right)$ and hemispheric backscattering $\left(\sigma_{\mathrm{bsp}}\right)$ coefficients at three wavelengths $(450$, 550 and $700 \mathrm{~nm}$ ). Instrument zero checks on filtered air were automatically performed hourly. Routine maintenance and instrument calibrations with $\mathrm{CO}_{2}$ were performed three times: once in July, another in January and again in June. The nephelometers are downstream of a switched impactor system which toggles the aerosol size cut between $1.0 \mu \mathrm{m}$ $\left(\mathrm{PM}_{1}\right)$ and $10 \mu \mathrm{m}\left(\mathrm{PM}_{10}\right)$ aerodynamic particle diameters every $30 \mathrm{~min}$. The first nephelometer measures the aerosol light-scattering coefficient at dry conditions $(\mathrm{RH}<40 \%)$ while the second nephelometer measures the aerosol lightscattering coefficient at a controlled RH. The sampled 
aerosol was gently heated when necessary to achieve a low $\mathrm{RH}$ of $40 \%$ or below. The mean \pm standard deviations of the temperature and relative humidity within the dry nephelometer for the whole measurement campaign were $T=26 \pm 4{ }^{\circ} \mathrm{C}$ and $\mathrm{RH}=30 \pm 13 \%$. In order to minimize losses of volatile compounds, the temperature of the sampled air was kept below $35^{\circ} \mathrm{C}$ (Bergin et al., 1997; ten Brink et al., 2000). Only $0.5 \%$ of the $1 \mathrm{~min}$ observations occurred at temperatures above this value and these data were not further considered in the study. The humidifier consists of two concentric tubes: the inner one is a high-density porous polytetrafluoroethylene (PTFE) tube and the outer tube is a stainless steel tube wrapped in a tape heater and insulation. A closed loop of water circulates between the PTFE and the outer tube. As the water temperature increases, water vapor moves through the semipermeable PTFE membrane causing the RH of the sample air to increase. The temperature of the water is regulated via a feedback system between the downstream RH sensor, the PID (proportionalintegral-derivative) controller and the heater. Temperature and relative humidity sensors (Vaisala model HMP110, accuracy of $\pm 3 \% \mathrm{RH}$ ) are placed throughout the system: one of the sensors is placed upstream of the impactor box and the other two sensors are placed immediately downstream of the reference and humidified nephelometers. The internal nephelometer TSI RH sensors are not used because of their slower time response and uncertainty. For this reason, the $\mathrm{RH}$ inside the nephelometer was calculated from the dew point temperature of the Vaisala sensor at the outlet of the humidified nephelometer and the internal nephelometer temperature. The instruments reported results at $1 \mathrm{~Hz}$ resolution, and the data were then averaged and recorded at $1 \mathrm{~min}$ resolution. The nephelometers operated at a volumetric flow rate of $30 \mathrm{~min}^{-1}$. Nonidealities due to truncation errors and the non-Lambertian light source were corrected according to Anderson and Ogren (1998). The uncertainty in the aerosol light-scattering coefficient is about $7 \%$ (Heintzenberg et al., 2006). Every hour the RH measurement cycle started with a zero measurement and then in the humidified nephelometer the RH was increased stepwise to $80-85 \%$ within $30 \mathrm{~min}$, and then decreased back to RH values of about $40 \%$ or below during the second half of the hour. The upward RH scan corresponded to the $\mathrm{PM}_{10}$ size cut and the downward RH scan to $\mathrm{PM}_{1}$. When both nephelometers measured at dry conditions $(\mathrm{RH}<40 \%)$ the two of them agreed well $\left(\mathrm{PM}_{10}\right.$ : slope $=1.073 \pm 0.001$, intercept $=0.48 \pm 0.02 \mathrm{Mm}^{-1}$ and $R^{2}=0.99 ; \quad \mathrm{PM}_{1}$ : slope $=0.971 \pm 0.004$, intercept $=0.68 \pm 0.04 \mathrm{Mm}^{-1}$ and $R^{2}=0.77$ (for the $550 \mathrm{~nm}$ wavelength)).

The aerosol light-absorption coefficient was measured with a particle soot absorption photometer (PSAP). The method is based on the integrating plate technique in which the change in optical transmission of a filter caused by particle deposition on the filter is related to the light-absorption coefficient of the deposited particles using the Beer-Lambert law. Here, a three-wavelength version of the PSAP has been used, with nominal wavelengths of 467, 531 and $650 \mathrm{~nm}$. The PSAP data were corrected according to Bond et al. (1999) and Ogren (2010). The uncertainty of the PSAP absorption measurement, after application of the transmission and scattering correction, is 20-30\% (Bond et al., 1999). The PSAP is also downstream of the switched impactors.

Ambient temperature, relative humidity, wind speed and direction were continuously monitored using the surface meteorological instrumentation (MET) data from the ARM AMF1 facility.

Air-mass back trajectories were computed using the HYSPLIT4 model (Hybrid Single Particle Lagrangian Integrated Trajectory; Draxler et al., 2009) version 4.9 and were used to support the interpretation of the data.

\section{Methodology}

Aerosol intensive properties, such as the single scattering albedo (SSA), the hemispheric backscatter fraction $(b)$, the submicron scattering fraction $\left(R_{\mathrm{sp}}\right)$ and scattering Ångström exponent (SAE), were calculated from the aerosol scattering and/or absorption coefficients.

The scattering Ångström exponent characterizes the wavelength dependence of $\sigma_{\mathrm{sp}}$ and was calculated using the 700 and $450 \mathrm{~nm}$ wavelength pair using the following equation:

$\operatorname{SAE}\left(\lambda_{1}-\lambda_{2}\right)=-\left(\log \sigma_{\mathrm{sp}}\left(\lambda_{1}\right)-\log \sigma_{\mathrm{sp}}\left(\lambda_{2}\right)\right) /\left(\log \lambda_{1}-\log \lambda_{2}\right)$

This variable increases with decreasing particle size and typically has values around 2 or higher when the scattering process is dominated by fine particles, while it is close to 0 when the scattering process is dominated by coarse particles (Delene and Ogren, 2002).

The submicron scattering fraction allows apportionment of light scattering into sub- and supermicrometer aerosol mode. It was calculated for the $550 \mathrm{~nm}$ wavelength as follows:

$R_{\mathrm{sp}}(\lambda)=\sigma_{\mathrm{sp}\left(D_{\mathrm{p}}<1 \mu \mathrm{m}\right)}(\lambda) / \sigma_{\mathrm{sp}\left(D_{\mathrm{p}}<10 \mu \mathrm{m}\right)}(\lambda)$.

The hemispheric backscatter fraction is the fraction of radiation that is scattered back at angles between 90 and $170^{\circ}$. This parameter increases with decreasing particle size.

$b(\lambda)=\sigma_{\mathrm{bsp}}(\lambda) / \sigma_{\mathrm{sp}}(\lambda)$

The aerosol single scattering albedo at the $550 \mathrm{~nm}$ wavelength is the ratio of the scattering and extinction coefficients. It was calculated using the following formula:

$\operatorname{SSA}(\lambda)=\sigma_{\mathrm{sp}}(\lambda) /\left(\sigma_{\mathrm{sp}}(\lambda)+\sigma_{\mathrm{ap}}(\lambda)\right)$

In order to determine SSA at $550 \mathrm{~nm}$, the absorption coefficient measured with the PSAP was interpolated to the $550 \mathrm{~nm}$ wavelength using the above described Angström formula. In this work, $\operatorname{SSA}(550), b(550), R_{\mathrm{sp}}(550)$ and 
SAE(450-700) refer always to dry conditions and to the $\mathrm{PM}_{10}$ size fraction.

To quantify the effect of water uptake in the aerosol light-scattering coefficient, the scattering enhancement factor $f(\mathrm{RH})$ defined as the ratio of $\sigma_{\mathrm{sp}}(\lambda)$ at a high and at reference RH ( $\lambda=550 \mathrm{~nm}$ in the present work) was used and calculated as follows:

$$
f(R H, \lambda)=\sigma_{\mathrm{sp}}(R H, \lambda) / \sigma_{\mathrm{sp}}(\mathrm{dry}, \lambda) .
$$

This study uses the following two-parameter equation (Clarke et al., 2002; Carrico et al., 2003) to describe the increase in aerosol scattering due to hygroscopic growth:

$f(\mathrm{RH})=a(1-\mathrm{RH})^{-\gamma}$,

where $a$ is the intercept at $\mathrm{RH}=0 \%$ and $\gamma$ parameterizes the magnitude of the scattering enhancement. To reduce the influence of instrument noise on the calculation, only values of the dry scattering coefficient above $5 \mathrm{Mm}^{-1}$ were considered in the calculation of $f(\mathrm{RH})$. The constraints imposed for the fitting were a lower RH of $40 \%$, a minimum span of $30 \% \mathrm{RH}$ in each scan, a minimum of $50 \%$ data coverage in each scan, the RH in the reference nephelometer had to be below $40 \%$ and a fit $R^{2}$ value above 0.5 . These criteria were applied for $\mathrm{PM}_{10}$ and $\mathrm{PM}_{1}$ size fractions, with each size fraction fitted separately. A total of $2952\left(\mathrm{PM}_{10}\right)$ and $1753\left(\mathrm{PM}_{1}\right)$ humidograms were successfully fitted for each size, respectively. Additionally, for each scan, $f(\mathrm{RH})$ values were calculated at $\mathrm{RH}=80 \%$ using Eq. (6), enabling comparison of scan hygroscopicity.

\section{Results and discussion}

\subsection{Overview of the campaign}

Mean ambient temperature and relative humidity during the campaign were $7 \pm 6^{\circ} \mathrm{C}$ and $80 \pm 20 \%$. Both variables presented clear diurnal patterns with higher temperature and lower RH values at midday. The wind speed ranged from calm winds up to values close to $20 \mathrm{~m} \mathrm{~s}^{-1}$ during specific periods, showing a mean campaign value of $5 \pm 3 \mathrm{~m} \mathrm{~s}^{-1}$. Winds from the west direction occurred more frequently. Figure 1 shows an overview of the daily average aerosol lightscattering and absorption coefficients, $\sigma_{\mathrm{sp}}(550)$ and $\sigma_{\mathrm{ap}}(531)$, single scattering albedo, SSA(550), and scattering Ångström exponent, $\mathrm{SAE}(450-700)$, in the $\mathrm{PM}_{10}$ fraction. For the entire campaign, the $\sigma_{\mathrm{sp}}(550)$ had a mean \pm standard deviation value of $22 \pm 15 \mathrm{Mm}^{-1}$ and the corresponding values for $\sigma_{\mathrm{ap}}(531)$ were $1.1 \pm 0.9 \mathrm{Mm}^{-1}$. In general, the aerosol light-absorption coefficient was very low during the measurement period, especially compared with the scattering coefficient; the SSA(550) had a mean value of $0.94 \pm 0.04$. However, daily-average SSA(550) values ranged from 0.77 to 1.0 , denoting periods where the contribution of absorption increased. The campaign-averaged SAE(450-700) was
$1.8 \pm 0.6$, which is quite high for a coastal environment compared with literature values (e.g., Carrico et al., 1998; FierzSchmidhauser et al., 2010b), and is an evidence of the influence of anthropogenic aerosols at Cape Cod during the TCAP campaign. In fact, the SAE(450-700) showed a high variability with daily values ranging from 0.6 to 3 . The submicron scattering fraction reported similar information with values ranging from 0.02 to 1 , indicating different atmospheric conditions dominated by different aerosol types (fine, coarse and mixed particles). Concerning the backscatter fraction, this variable had a mean campaign value of $0.13 \pm 0.02$. The SAE(450-700), $R_{\mathrm{sp}}(550)$ and $b(550)$ report similar information since all three parameters are related to aerosol mean size (Fan et al., 2010). In fact, the SAE(450-700) had a strong correlation with $R_{\mathrm{sp}}\left(R^{2}=0.81\right)$ and a moderate correlation with $b\left(R^{2}=0.5\right)$, both at $550 \mathrm{~nm}$. For this reason, in the following sections we will focus on the scattering Ångström exponent as indicator of particle size.

None of the variables mentioned above showed a clear diurnal pattern, presenting very small changes throughout the day. In addition, no clear temporal trend was observed throughout the study period, although certain events of elevated $\sigma_{\mathrm{sp}}(550)$ were observed connected with high SSA(550) values and low SAE(450-700) values. These events occurred under high wind speeds and were probably caused by sea salt particles (large particles with minimal absorption). As an example, on 9 March the $\sigma_{\mathrm{sp}}(550)$ reached its maximum value (daily average of $84 \mathrm{Mm}^{-1}$ ). On this day the SSA had a mean value of 1 and the SAE was 0.75 , suggesting that the aerosol optical properties were dominated by coarse, purely scattering particles.

Figure 2 shows the aerosol light-scattering enhancement factor $f(\mathrm{RH}=80 \%)$ (upper panel) and the $\gamma$ parameter (lower panel) calculated for the $\mathrm{PM}_{10}$ and $\mathrm{PM}_{1}$ fractions at $550 \mathrm{~nm}$ (hereafter the wavelength will be omitted in the notation for simplicity). Over the period of measurement, $f(\mathrm{RH}=80 \%)$ had a mean value of $1.9 \pm 0.3$, with dailymean values ranging from 1.4 to 2.6 in the $\mathrm{PM}_{10}$ fraction. In the $\mathrm{PM}_{1}$ fraction, $f(\mathrm{RH}=80 \%)$ had a mean value of $1.8 \pm 0.4$ and ranged from 1.2 to 3.4. Average $\gamma$ values were 0.5 for both size fractions but were relatively more variable in the $\mathrm{PM}_{1}$ fraction (in $\mathrm{PM}_{1}$, daily $\gamma$ values ranged from 0.1 to 1.1 , and in $\mathrm{PM}_{10}$ ranged from 0.2 and 0.9 ). The temporal trend of $f(\mathrm{RH}=80 \%)$ and $\gamma$ was similar in both size fractions, however, larger differences between $\mathrm{PM}_{10}$ and $\mathrm{PM}_{1}$ were observed for specific events. Specifically, on 9 March this difference was considerably larger with a mean daily $f(\mathrm{RH}=80 \%)$ of 3.1 in $\mathrm{PM}_{1}$ compared to 2.4 in $\mathrm{PM}_{10}$. On this day, the air-mass back trajectories arriving at $500 \mathrm{~m}$ a.g.l. at the measurement station were coming from the Atlantic Ocean and traveled at low altitude for the last 3 days, likely picking up sea salt particles. In order to investigate in more detail the differences in the magnitude of the scattering enhancement between the fine and coarse fractions, Figure 3 shows the hourly $f(\mathrm{RH}=80 \%)$ values in 


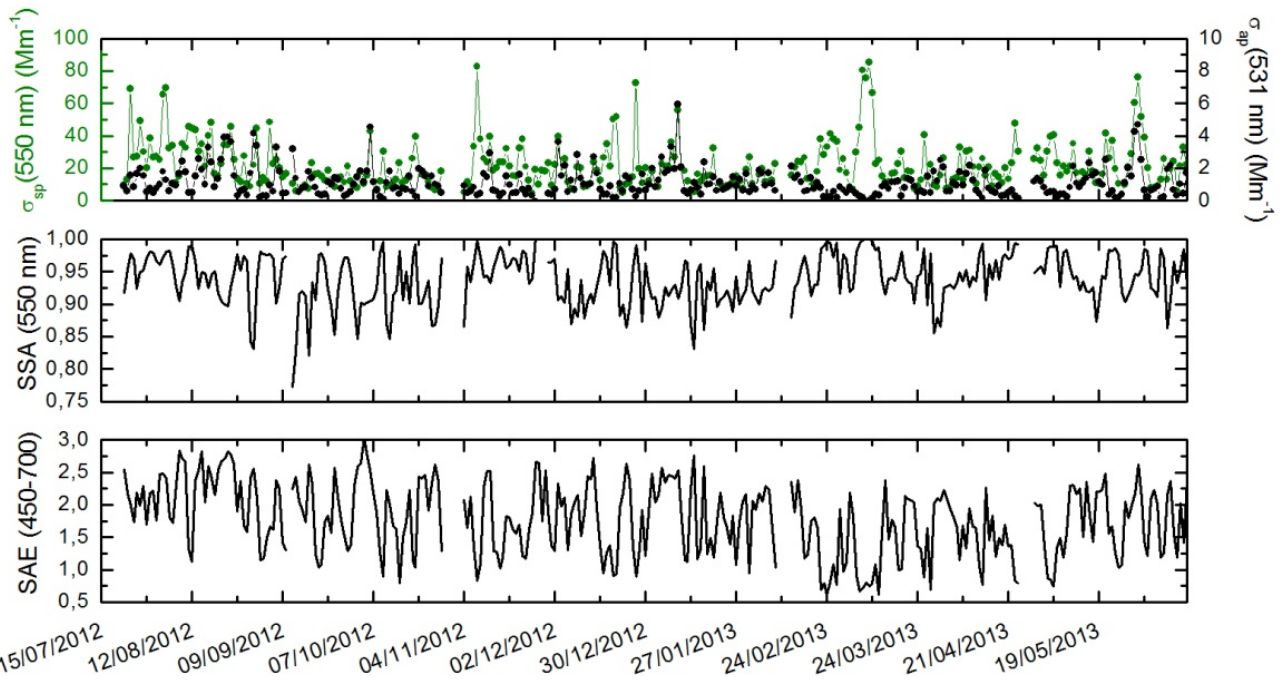

Figure 1. Temporal evolution of the daily dry scattering and absorption coefficients (upper panel), the single scattering albedo (middle panel) and the scattering Ångström exponent (lower panel). All the parameters correspond to the PM $_{10}$ fraction. The date is in the format $\mathrm{dd} / \mathrm{mm} / \mathrm{yyyy}$.

$\mathrm{PM}_{1}$ vs. $f(\mathrm{RH}=80 \%)$ values in $\mathrm{PM}_{10}$. Data when the $\mathrm{SAE}$ (at dry conditions and in the $\mathrm{PM}_{10}$ fraction) was below and above 1, denoting a predominance of larger and smaller particles, respectively, were fitted separately. The graph shows that in the situation dominated by aerosol sea salt $(\mathrm{SAE}<1)$ the scattering in the $\mathrm{PM}_{1}$ fraction experienced a higher enhancement than in the $\mathrm{PM}_{10}$ fraction. The same behavior was also found for the $\gamma$ parameter (not shown). This indicates that small sea salt particles have a larger scattering enhancement compared to coarse sea salt particles. This result is supported by theoretical calculations of hygroscopic growth as a function of particle size for common aerosol salts and acids made by Zieger et al. (2013). These authors showed that $f(\mathrm{RH}=85 \%)$ increases with decreasing particle size for all components studied, but increases more dramatically for $\mathrm{NaCl}$, the largest component in sea salt. However, this behavior can be also explained by a shift in the size distribution to a scattering regime with a higher scattering efficiency when the SAE is greater than 1 .

A total of 2952 and $1753 \mathrm{RH}$ scans in $\mathrm{PM}_{10}$ and $\mathrm{PM}_{1}$ fractions, respectively, were fitted according to the criteria explained in Sect. 3. Additional fits were performed for the RH ranges below and above $65 \%$. The values of $\gamma>65 \%$ and $\gamma<65 \%$ were used to identify possible deliquescence transitions. Similar values of $\gamma_{>65 \%}$ and $\gamma<65 \%$ indicate a monotonic growth for the entire $\mathrm{RH}$ range, while distinct values $\left(\gamma_{<65 \%} \ll \gamma>65 \%\right)$ indicate no significant enhancement below $65 \%$ and a large increase at an RH value above $65 \%$. For those cases in which $\gamma<65 \% \ll \gamma>65 \%$ the fit using the entire RH range underestimated $f(\mathrm{RH})$ values at both low and high RH and overestimated $f(\mathrm{RH})$ at the transition $\mathrm{RH}$ (around $65-75 \%$ RH). To illustrate this, Fig. 4a and b show the daily average humidograms for two different cases dominated by deliquescent and nondeliquescent particles, respectively. Figure $4 \mathrm{a}$ shows the 9 March daily average humidogram scan $\left(\gamma=0.8, \gamma_{<65 \%}=0.4\right.$ and $\left.\gamma_{>65 \%}=1.1\right)$ and Fig. $4 \mathrm{~b}$ shows the daily average humidogram scan of 31 May $(\gamma=0.3$, $\gamma<65 \%=0.3$ and $\left.\gamma_{>65 \%}=0.4\right)$. On 9 March the scattering enhancement for $\mathrm{RH}>65 \%$ was almost threefold the enhancement for $\mathrm{RH}<65 \%$. As mentioned before, during this day there was a predominance of nonabsorbing coarse particles $($ mean $\operatorname{SAE}(450-700)=0.75$ and $\operatorname{SSA}(550)=1)$, suggesting a clear contribution of deliquescent sea salt particles. However, on 31 May the scattering enhancement was similar for both RH ranges. Slightly darker, nondeliquescent fine mode particles dominated the aerosol on 31 May (SAE(450$700)=1.8, \operatorname{SSA}(550)=0.91)$ compared with the previous case. Concerning the " $a$ " parameter, it varies with the aerosol transmission efficiency through the humidifier and goodness of the power-law fit. Differences between the experimental and ideal value of " $a$ " are expected since the " $a$ " value will depend also on aerosol losses in the dry nephelometer and in the humidifier system. In this study, fitting the whole RH range for deliquescent aerosols seems to be inadequate. Nevertheless, fitting $f(\mathrm{RH})$ to multiple $\mathrm{RH}$ ranges offers information on aerosol deliquescence properties.

\subsection{Influence of wind speed and direction on the aerosol hygroscopicity}

In order to evaluate the influence of wind speed and direction on aerosol hygroscopic properties, Fig. 5 shows bivariate plots of $f(\mathrm{RH}=80 \%), \gamma, \operatorname{SSA}(550)$ and $\operatorname{SAE}(450-700)$ as a function of wind speed and direction (Openair software; Carslaw and Ropkins, 2012). Both $f(\mathrm{RH}=80 \%)$ and $\gamma$ increased with wind speed. SSA(550) and SAE(450-700) have 

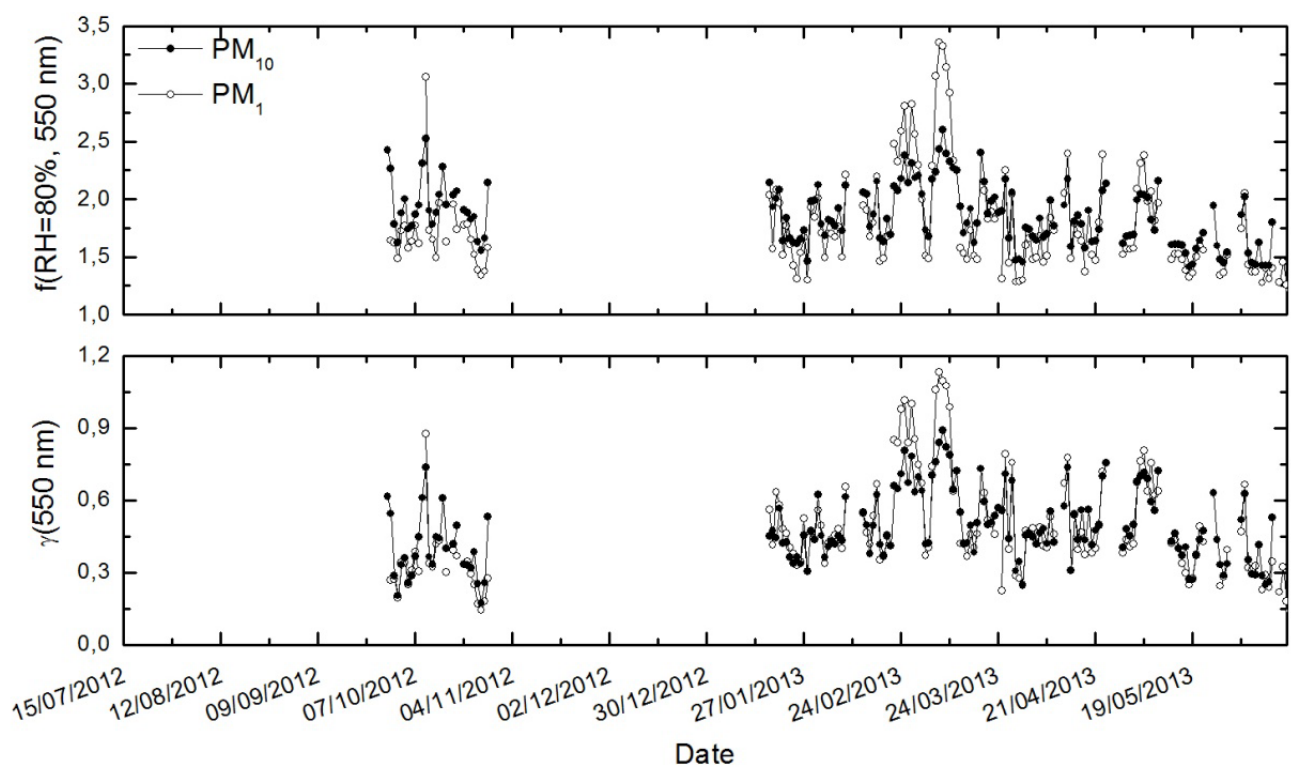

Figure 2. Temporal evolution of the daily scattering enhancement factor at $80 \%$ relative humidity (upper panel) and the fit parameter $\gamma$ (lower panel), for $\mathrm{PM}_{10}$ and $\mathrm{PM}_{1}$ fractions. The date is in the format $\mathrm{dd} / \mathrm{mm} / \mathrm{yyyy}$.

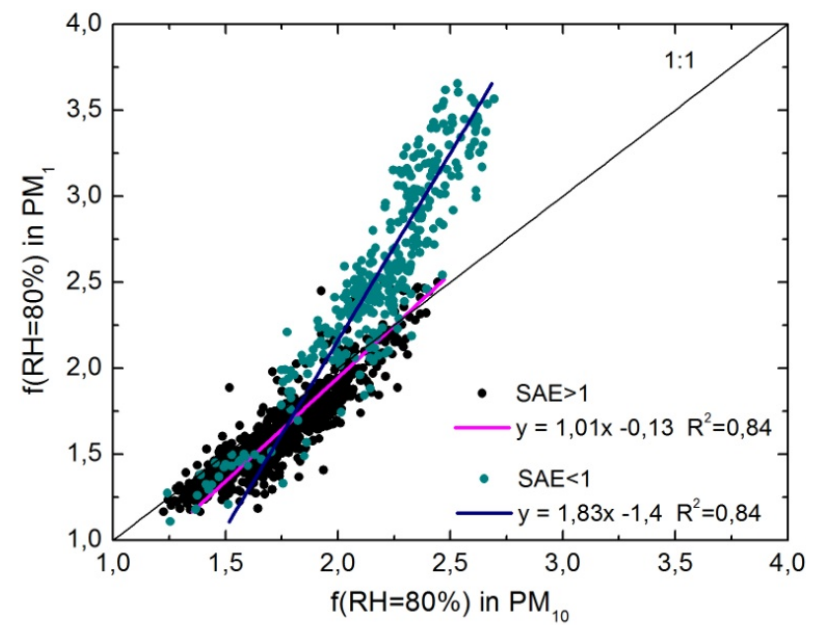

Figure 3. Scatter plot of the hourly average scattering enhancement factors at $80 \%$ relative humidity in the $\mathrm{PM}_{1}$ fraction vs. the same parameter in the $\mathrm{PM}_{10}$ fraction. Data when the scattering Ångström exponent was below and above 1 were fitted separately.

opposite trends to each other, with increasing SSA(550) values and decreasing SAE(450-700) with wind speed. These plots show that there is a region between approximately 225 and $315^{\circ}$, characterized by lower SSA(550) and higher SAE(450-700), probably influenced by anthropogenic air from the populated urban areas of Providence and Boston. In contrast, the region from 0 to $180^{\circ}$, characterized by higher SSA(550) and lower SAE(450-700), was characterized by marine-dominated aerosols from the North Atlantic Ocean. According to these results, two wind sectors have been considered for further investigation: the marine sector $\left(0-180^{\circ}\right)$ and the anthropogenically influenced sector $\left(225-315^{\circ}\right)$. For this analysis, only wind speed values above $5 \mathrm{~m} \mathrm{~s}^{-1}$ were considered in order to avoid local influences. The marine wind sector was characterized by slightly higher temperatures and $\mathrm{RH}$ values (median values: $T=4.9^{\circ} \mathrm{C}$ and $\mathrm{RH}=89 \%$ ) than the anthropogenically influenced wind sector $\left(T=2.4{ }^{\circ} \mathrm{C}\right.$ and $\left.\mathrm{RH}=58 \%\right)$. This last sector also showed a higher variability in the temperature values. Table 1 summarizes the mean and standard deviation of the aerosol optical parameters for each sector. There is a clear difference between both wind sectors when looking at the aerosol intensive properties. The anthropogenically influenced sector was characterized by smaller and more absorbing particles with similar $f(\mathrm{RH}=80 \%)$ for both size fractions. Furthermore, for the anthropogenically influenced sector, $\gamma_{>} 65 \%$ and $\gamma<65 \%$ were very similar denoting no distinct deliquescent behavior. The marine sector presented very different properties compared with the anthropogenic sector: it was characterized by larger and very weakly absorbing particles (see Table 1). The $f(\mathrm{RH}=80 \%)$ was higher in the $\mathrm{PM}_{1}$ than $\mathrm{PM}_{10}$ fraction, denoting a larger scattering enhancement in the fine mode. In addition, $\gamma_{>} 65 \%$ was considerably higher $(0.9 \pm 0.2)$ than $\gamma_{<65 \%}(0.4 \pm 0.1)$, evidence of deliquescent aerosols. Carrico et al. (2000) also observed a higher scattering enhancement for clean marine conditions than for polluted situations (see Table 2) in Sagres (Portugal) which agrees with the results obtained in this section (Table 1) and those shown in Fig. 3. The $f(\mathrm{RH})$ values reported here for clean and anthropogenically influenced marine aerosols are in agreement with the range of values reported in the literature (Table 2). 
a)

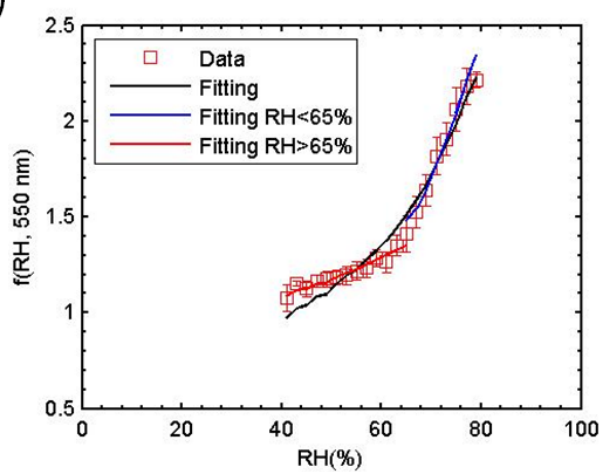

b)

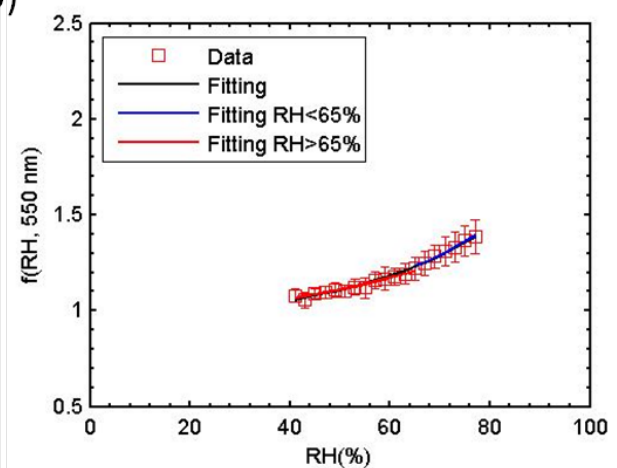

Figure 4. Example humidograms of the scattering enhancement factor, given as daily averages where the error bars represent the standard deviation for 9 March (a) and 31 May (b). The black line denotes the $\gamma$ fit for the entire RH range (RH $>40 \%)$, the blue line denotes the $\gamma$ fit for $\mathrm{RH}>65 \%$ and the red line the $\gamma$ fit for the $\mathrm{RH}<65 \%$.

Table 1. Mean and standard deviation of single scattering albedo, scattering Ångström exponent, $\gamma$ parameter, $\gamma>65 \%, \gamma<65 \%$ and scattering enhancement factor at $80 \% \mathrm{RH}$ for $\mathrm{PM}_{10}$ fraction and scattering enhancement factor at $80 \% \mathrm{RH}$ for $\mathrm{PM}_{1}$ fraction for the two wind sectors. All the variables refer to $550 \mathrm{~nm}$ except the scattering Ångström exponent that has been calculated between 450 and $700 \mathrm{~nm}$.

\begin{tabular}{lccccccc}
\hline Sector & SSA & SAE & $\gamma$ & $\gamma>65 \%$ & $\gamma<65 \%$ & $f(\mathrm{RH}=80 \%)$ & $f(\mathrm{RH}=80 \%)$ in $\mathrm{PM}_{1}$ \\
\hline Anthropogenic & $0.93 \pm 0.03$ & $1.8 \pm 0.5$ & $0.4 \pm 0.1$ & $0.5 \pm 0.2$ & $0.4 \pm 0.1$ & $1.8 \pm 0.2$ & $1.7 \pm 0.2$ \\
Marine & $0.98 \pm 0.02$ & $0.9 \pm 0.3$ & $0.7 \pm 0.1$ & $0.9 \pm 0.2$ & $0.4 \pm 0.1$ & $2.2 \pm 0.3$ & $2.5 \pm 0.6$ \\
\hline
\end{tabular}
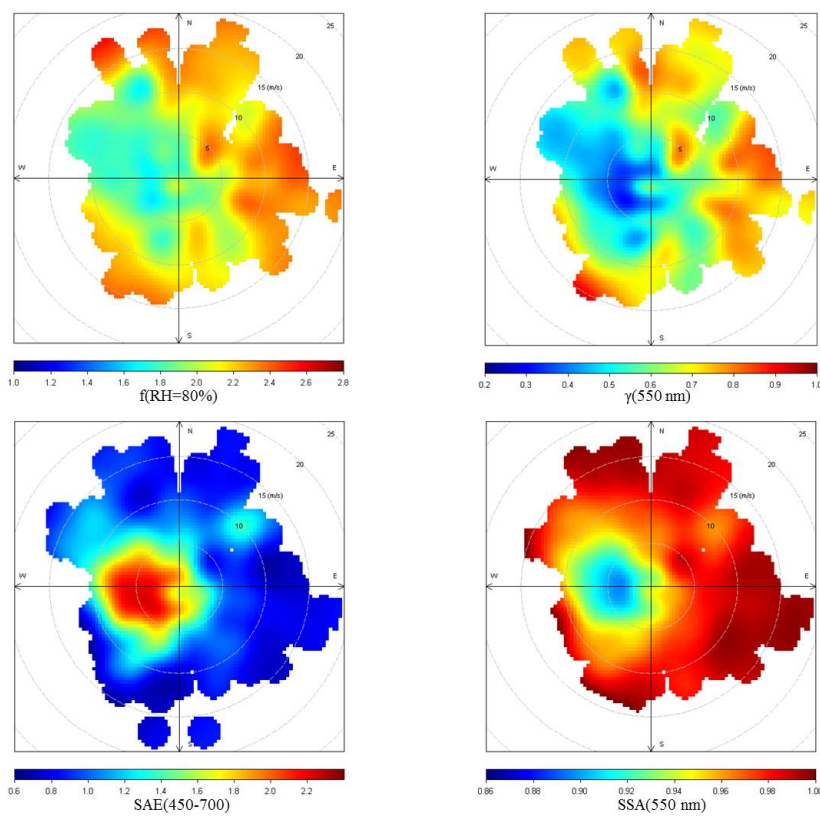

Figure 5. Bivariate plots of the scattering enhancement factor at $80 \% \mathrm{RH}$, the $\gamma$ parameter, single scattering albedo and scattering Ångström exponent as a function of wind speed and direction.

\subsection{Air-mass trajectories classification}

A cluster analysis of 3-day air-mass back trajectories arriving at Cape Cod at $500 \mathrm{~m}$ a.g.l. (above ground level) at 00:00, 06:00, 12:00 and 18:00 GMT (Greenwich mean time) using the HYSPLIT4 model (Draxler et al., 2009) version 4.9 was performed to identify the main air-mass types affecting the area and their respective aerosol optical properties. This method is based on the geometric distance between individual trajectories and it takes into account speed and direction of the trajectory and height at the arriving location. A total of 1344 backward trajectories were used in the analysis. The number of clusters was selected according to the percentage change in total spatial variance (TSV). Large changes in the TSV were interpreted as the merging of significantly different trajectories into the same cluster. According to this criterion, the cluster analysis resulted in five clusters of back trajectories for air masses arriving at Cape Cod at low level. Figure 6 shows the clusters obtained with this analysis and the average humidogram for each cluster. The humidograms represent $f(\mathrm{RH})$ averages in $2 \% \mathrm{RH}$ size bins and the error bars represent the standard deviation in the $\mathrm{PM}_{10}$ fraction. Table 3 shows, for each cluster, the mean and standard deviation of the optical parameters. Clusters 1-4 exhibited similar aerosol optical properties with only small differences. Cluster 5 was characterized by small SAE(450-700) and high SSA(550), as well as by high $\gamma$ and $f(\mathrm{RH}=80 \%)$ values. The air masses included in this cluster came from the 
Table 2. Hygroscopic growth factors reported in the literature for marine environments. The values of $f(\mathrm{RH})$ corresponds to the ratio of the aerosol light-scattering coefficients (near $550 \mathrm{~nm}$ wavelength) at high $\mathrm{RH}\left(85 \%\right.$ unless noted: $\left.{ }^{*} \mathrm{RH}=82 \%,{ }^{* *} \mathrm{RH}=80 \%\right)$ and at dry conditions $(\mathrm{RH}<40 \%)$. All samples were taken with a size cut $\left(D_{\mathrm{p}}\right)$ of $10 \mu \mathrm{m}$ unless specifically noted.

\begin{tabular}{|c|c|c|c|c|}
\hline Source & Location & Year & $f(\mathrm{RH})$ & Notes \\
\hline Hegg et al. (1996) & eastern North Pacific Ocean & 1994 & $2.3^{* *}$ & $\begin{array}{l}\text { No } D_{\mathrm{p}} \text { cut } \\
\text { Clean marine }\end{array}$ \\
\hline Li-Jones et al. (1998) & Barbados, West Indies & 1994 & $1.8^{* *}$ & Sea salt \\
\hline Carrico et al. (1998) & Cape Grim, Tasmania & 1995 & $1.98^{*}$ & Clean marine \\
\hline McInnes et al. (1998) & Sable Island, Canada & 1996 & $\begin{array}{l}2.7 \\
1.7\end{array}$ & $\begin{array}{l}D_{\mathrm{p}}<1 \mu \mathrm{m} \\
\text { Marine } \\
\text { Polluted }\end{array}$ \\
\hline Kotchenruther et al. (1999) & western North Atlantic Ocean & 1996 & $\begin{array}{l}1.81^{* *} \\
2.30^{* *}\end{array}$ & $\begin{array}{l}D_{\mathrm{p}}<4 \mu \mathrm{m} \\
\text { "less anthropogenic" } \\
\text { "more anthropogenic" }\end{array}$ \\
\hline Carrico et al. (2000) & Sagres, Portugal & 1997 & $\begin{array}{l}1.69^{*} \\
1.46^{*} \\
1.86^{*} \\
1.48^{*}\end{array}$ & $\begin{array}{l}D_{\mathrm{p}}<10 \mu \mathrm{m} \\
\text { Clean } \\
\text { Polluted } \\
D_{\mathrm{p}}<1 \mu \mathrm{m} \\
\text { Clean } \\
\text { Polluted }\end{array}$ \\
\hline Gassó et al. (2000) & eastern North Atlantic Ocean & 1997 & $\begin{array}{l}2.0^{* *} \\
2.5^{* *}\end{array}$ & $\begin{array}{l}D_{\mathrm{p}}<2.5 \mu \mathrm{m} \\
\text { Polluted } \\
\text { Clean }\end{array}$ \\
\hline Sheridan et al. (2002) & $\begin{array}{l}\text { Indian Ocean } \\
\text { Indian Ocean (north) } \\
\text { Indian Ocean (central) } \\
\text { Southern Hemisphere }\end{array}$ & 1999 & $\begin{array}{l}1.55 \\
1.69 \\
2.07\end{array}$ & $\begin{array}{l}D_{\mathrm{p}}<1 \mu \mathrm{m} \\
\text { Polluted } \\
\text { Polluted } \\
\text { Clean marine }\end{array}$ \\
\hline Carrico et al. (2003) & Asia/Pacific region & 2001 & $\begin{array}{l}2.45^{*} \\
2.24^{*} \\
2.95^{*} \\
2.52^{*}\end{array}$ & $\begin{array}{l}D_{\mathrm{p}}<10 \mu \mathrm{m} \\
\text { Marine } \\
\text { Polluted } \\
D_{\mathrm{p}}<1 \mu \mathrm{m} \\
\text { Marine } \\
\text { Polluted }\end{array}$ \\
\hline Fierz-Schmidhauser et al. (2010b) & Mace Head, Ireland & 2009 & $\begin{array}{l}2.2 \\
1.8\end{array}$ & $\begin{array}{l}\text { Clean } \\
\text { Polluted }\end{array}$ \\
\hline Zieger et al. (2011) & Cabauw, the Netherlands & 2009 & 3 & Maritime \\
\hline This study & Cape Cod, MA & 2012-2013 & $\begin{array}{l}2.2^{* *} \\
1.8^{* *} \\
2.5^{* *} \\
1.7^{* *}\end{array}$ & $\begin{array}{l}D_{\mathrm{p}}<10 \mu \mathrm{m} \\
\text { Clean marine } \\
\text { Anthropogenic } \\
D_{\mathrm{p}}<1 \mu \mathrm{m} \\
\text { Clean marine } \\
\text { Anthropogenic }\end{array}$ \\
\hline
\end{tabular}



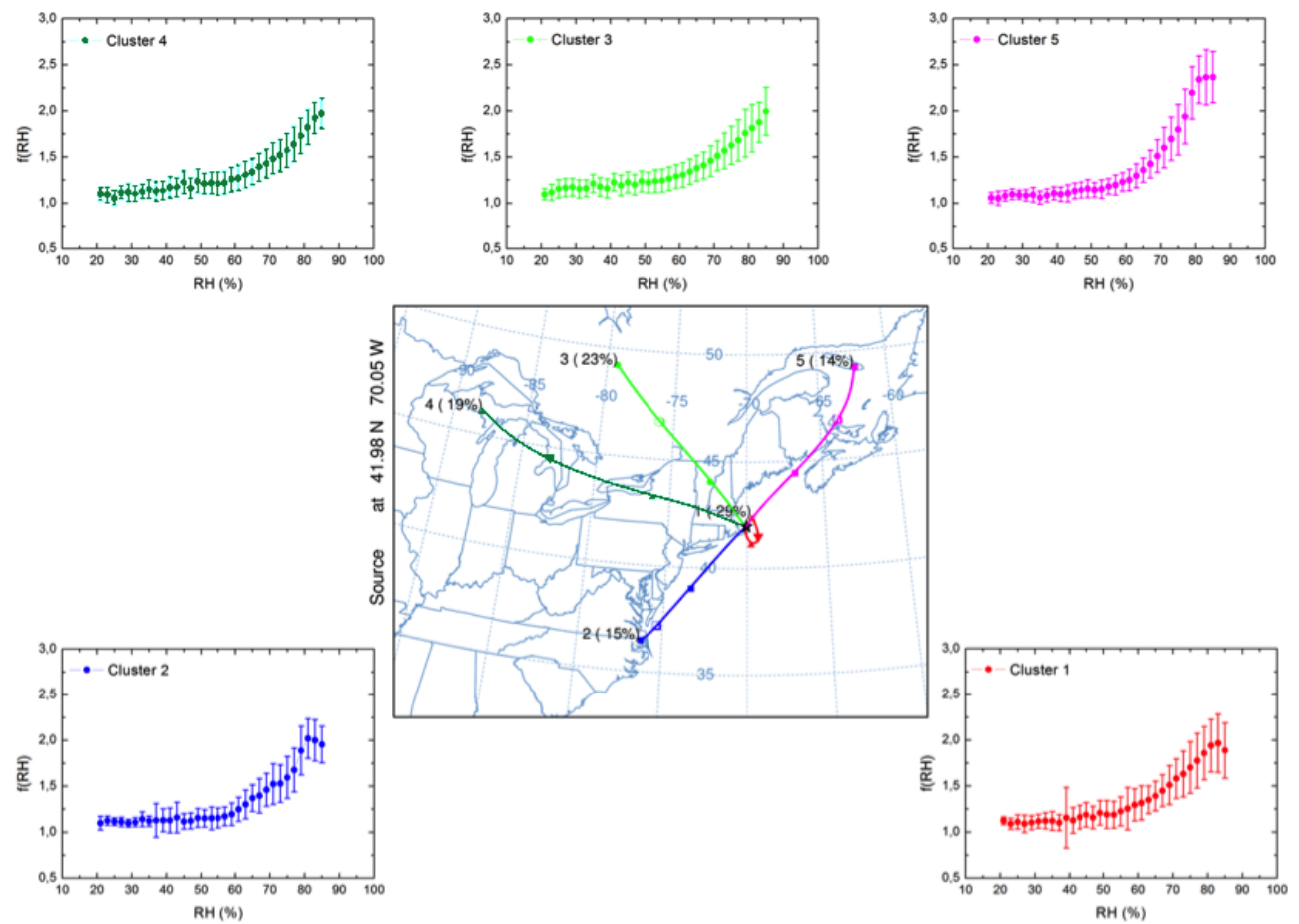

Figure 6. Clusterization of 3-day air-mass back trajectories arriving at Cape Cod at 500 m a.g.1. at 00:00, 06:00, 12:00 and 18:00 GMT according to the HYSPLIT4 model (central panel) and average humidograms for each cluster. The error bars denote the standard deviation.

northeast, some of them originating as far away as Greenland, passing over sparsely populated regions and the Atlantic Ocean. The high SAE(450-700) for cluster 4 together with a lower SSA(550) denotes an anthropogenic influence. Clusters 3 and 4 had similar characteristics in terms of the aerosol optical properties (see Fig. 6; Table 3). Both clusters comprise continental air masses. Clusters 1 and 2 had hybrid properties: with a predominance of larger particles compared to clusters 3 and 4 and with higher SSA values. This is probably because the air masses in clusters 1 and 2 passed over open ocean but originated in polluted continental regions. The cluster to cluster variation in the aerosol optical properties can be explained by the degree of anthropogenic and marine influence in the air masses included in each cluster.

\subsection{Relationship between $\gamma$ and SSA and SAE}

Predictive capability and global coverage of aerosol hygroscopicity for use in climate models would be enhanced if other aerosol parameters could be used as proxies to estimate hygroscopic growth. Toward this goal, we examined covariances between $\gamma$ and aerosol intensive properties. Figure 7 shows the frequency distribution of $\gamma$ in the $\mathrm{PM}_{10}$ fraction for different SAE and SSA ranges. Values of SAE(450-700) below 1 denote a higher predominance of coarse particles and lower SSA(550) values indicate darker aerosols. From Fig. $7 b$, it is clear that aerosols containing a higher fraction of absorbing particles (lower SSA) are less hygroscopic since the frequency distribution is shifted towards lower $\gamma$ values. In contrast, Fig. 7a suggests that when coarse aerosols predominate $(\mathrm{SAE}<1)$ the hygroscopic enhancement is larger. In general, $\gamma$ decreased as the contribution of coarse particles decreased, that is, as SAE increased (the correlation coefficient of $\gamma$ vs. SAE was $R=-0.77$ ). This result contrasts with the result of Zieger et al. (2010) that showed a decrease of $\gamma$ for an increase in the contribution of coarse particles ( $R=0.34$ ), probably connected with compensating effects of different varying aerosol properties during their study.

Because the $\gamma$ frequency distribution segregates well between high and low values of SSA and SAE, these variables seem to be good candidates as proxies to estimate the scattering enhancement due to water uptake. Based on the previous results, the following question arises: can the aerosol hygroscopicity be predicted based on dry optical properties? To answer this question, Fig. 8 (upper panel) shows $\gamma$ vs. SSA(550) where the color code represents the range of $\mathrm{SAE}(450-700)$. Figure $8 \mathrm{a}$ refers to $\gamma$ in $\mathrm{PM}_{1}$ and Fig. $8 \mathrm{~b}$ refers to $\gamma$ in $\mathrm{PM}_{10}$. In both $\gamma$ graphs, $\mathrm{SAE}(450-700)$ and $\mathrm{SSA}(550)$ correspond to the $\mathrm{PM}_{10}$ size fraction and to dry conditions. The $\mathrm{PM}_{1} \gamma$ was referenced to $\mathrm{PM}_{10}$ SSA and SAE as a means to make the fits applicable to surface measurements which may have only $\mathrm{PM}_{10}$ data and still differentiate the total and fine mode aerosol for models. As SSA(550) values increase the contribution of coarse particles also increases and these particles become more hygroscopic (bluish colors in Fig. 8). The increase of $\gamma$ with SSA in $550 \mathrm{~nm}$ 
Table 3. Mean and standard deviation of single scattering albedo, scattering Ångström exponent, $\gamma$ parameter, $\gamma>65 \%, \gamma<65 \%$ and scattering enhancement factor at $80 \% \mathrm{RH}$ for the five clusters. All the variables refer to $\mathrm{PM}_{10}$ unless specifically noted and to $550 \mathrm{~nm}$ except the scattering Ångström exponent that has been calculated between 450 and $700 \mathrm{~nm}$.

\begin{tabular}{cccccccc}
\hline Cluster & SSA & SAE & $\gamma$ & $\gamma>65 \%$ & $\gamma<65 \%$ & $f(\mathrm{RH}=80 \%)$ & $f(\mathrm{RH}=80 \%)$ in $\mathrm{PM}_{1}$ \\
\hline 1 & $0.94 \pm 0.04$ & $1.9 \pm 0.7$ & $0.5 \pm 0.2$ & $0.6 \pm 0.3$ & $0.4 \pm 0.1$ & $1.9 \pm 0.3$ & $1.8 \pm 0.4$ \\
2 & $0.95 \pm 0.04$ & $1.8 \pm 0.6$ & $0.5 \pm 0.1$ & $0.5 \pm 0.2$ & $0.4 \pm 0.1$ & $1.9 \pm 0.3$ & $1.8 \pm 0.3$ \\
3 & $0.92 \pm 0.04$ & $1.9 \pm 0.5$ & $0.4 \pm 0.1$ & $0.6 \pm 0.2$ & $0.4 \pm 0.1$ & $1.7 \pm 0.2$ & $1.6 \pm 0.3$ \\
4 & $0.92 \pm 0.03$ & $2.1 \pm 0.5$ & $0.4 \pm 0.1$ & $0.5 \pm 0.2$ & $0.4 \pm 0.1$ & $1.8 \pm 0.2$ & $1.7 \pm 0.2$ \\
5 & $0.97 \pm 0.03$ & $1.1 \pm 0.5$ & $0.7 \pm 0.2$ & $0.9 \pm 0.2$ & $0.4 \pm 0.1$ & $2.1 \pm 0.3$ & $2.5 \pm 0.6$ \\
\hline
\end{tabular}

a)

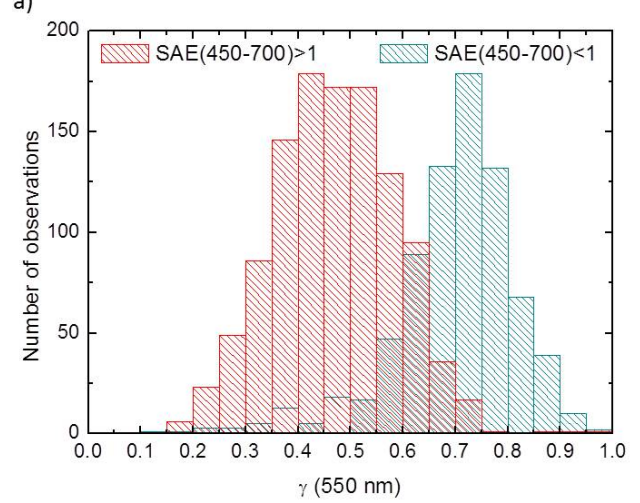

b)

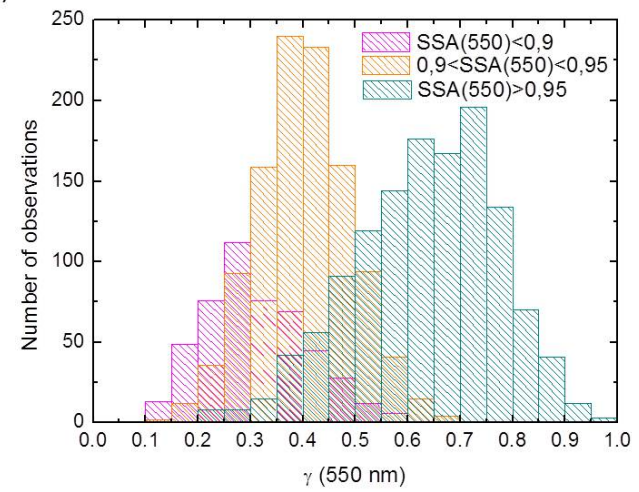

Figure 7. Frequency distribution of the $\gamma$ parameter for different scattering Ångström exponent (a) and single scattering albedo (b) ranges in the $\mathrm{PM}_{10}$ size fraction.

wavelength is well described by the following exponential functions for the $\mathrm{PM}_{1}$ (Eq. 7) and $\mathrm{PM}_{10}$ (Eq. 8) size fractions, respectively:

$$
\begin{gathered}
\gamma=(3 \pm 5) \cdot 10^{-15} \mathrm{e}^{\frac{\text { SSA }}{(0.030 \pm 0.001)}}+(0.31 \pm 0.01), \\
\gamma=(4 \pm 3) \cdot 10^{-9} \mathrm{e}^{\frac{\text { SSA }}{(0.054 \pm 0.002)}}+(0.26 \pm 0.01) .
\end{gathered}
$$

The coefficient of determination was $R^{2}=0.76$ in $\mathrm{PM}_{1}$ and $R^{2}=0.77$ in $\mathrm{PM}_{10}$. The increase observed in $\gamma$ for higher $\mathrm{SSA}(550)$ values is more pronounced in the $\mathrm{PM}_{1}$ than in the $\mathrm{PM}_{10}$ size fractions. Figure 8 (lower panel) shows the frequency distribution of the residuals for the fit in $\mathrm{PM}_{1}$ and in $\mathrm{PM}_{10}$, respectively, in order to assess the quality of the regression. About $79 \%$ of the $\gamma$ values in $\mathrm{PM}_{1}$ and $92 \%$ in $\mathrm{PM}_{10}$ were estimated by the model with a difference of \pm 0.15 in $\gamma$. The residuals did not exhibit any dependence on SAE, suggesting that the exponential fit captures most of the covariance between SAE and SSA. The potential of this model lies in its simplicity, as the aerosol hygroscopicity can be estimated by a single parameter, the dry singlescattering albedo. Quinn et al. (2005) proposed a parameterization based on the aerosol chemical composition, in particular, in the fraction of particulate organic matter to predict $f(\mathrm{RH})$. Also based on the chemical composition, Garland et al. (2007) reported that the $f(\mathrm{RH}=80 \%)$ varied linearly with the organic/inorganic content. However, measurements of aerosol chemical composition are commonly performed once a week and integrated over a $24 \mathrm{~h}$ period whereas optical properties are continuously measured at high time resolution. In this particular study, the coarse mode was predominantly dominated by sea salt particles and the presence of other species that typically accumulate in the coarse fraction like dust particles was negligible. Due to the similar characteristics of sea salt and dust particles in terms of SAE and SSA, but a strong difference in the hygroscopic behavior, the parameterization proposed in this study would fail under the presence of both types of aerosols as pure dust aerosols does not experience significant hygroscopic growth. The Cape Cod study may be considered as representative of an aerosol from the northern Atlantic coast with anthropogenic influence. The same analysis needs to be applied to other regions and aerosol types to catalog exponential fit parameters of $\gamma$ vs. SSA over a variety of aerosol types and atmospheric conditions.

\section{Conclusions}

The measured $f(\mathrm{RH})$ dependency with RH during the TCAP campaign can be well described with an empirical twoparameter fit equation for both size fractions $\left(\mathrm{PM}_{1}\right.$ and $\left.\mathrm{PM}_{10}\right)$. During the study period, $f(\mathrm{RH}=80 \%)$ and the fit 
a)
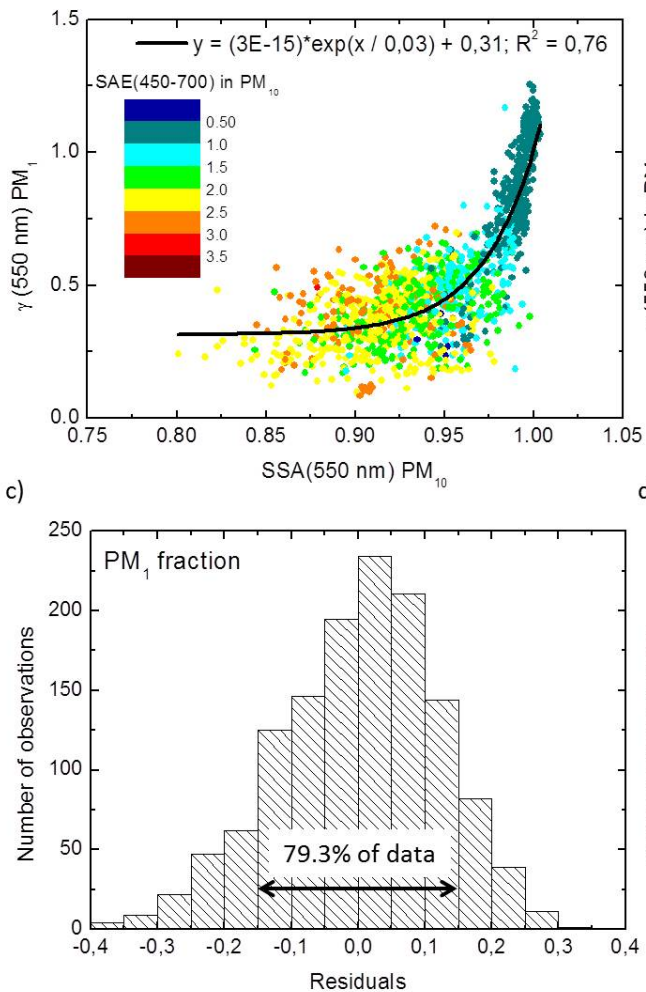
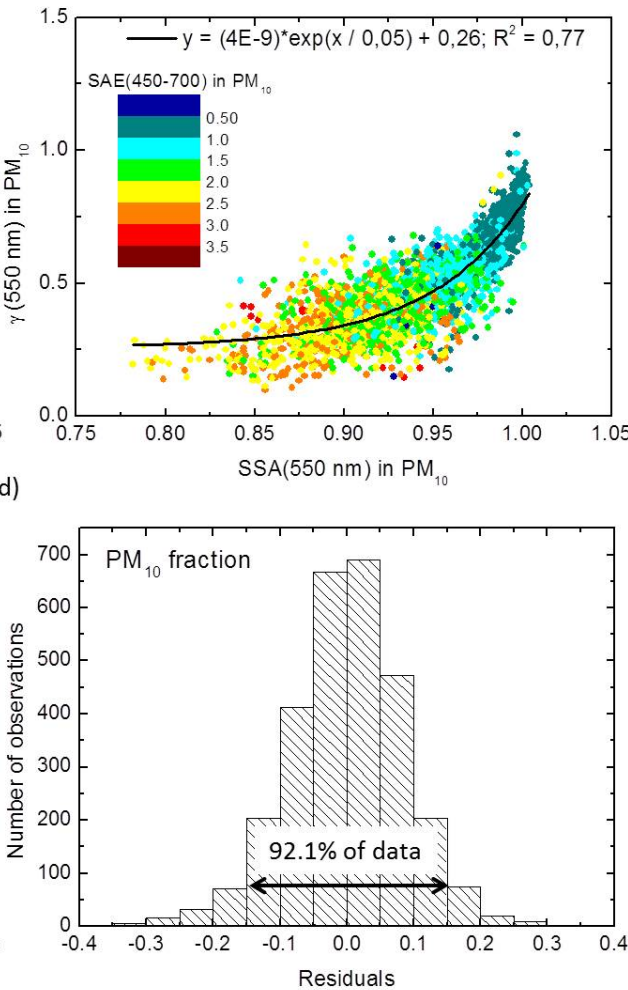

Figure 8. $\gamma$ parameter in $\mathrm{PM}_{1}$ (a) and $\mathrm{PM}_{10}$ (b) vs. the single scattering albedo in $\mathrm{PM}_{10}$. The color code corresponds to the scattering Ångström exponent in $\mathrm{PM}_{10}$. An exponential fit has been added to the plot (black line). The residuals of these regressions are plotted as frequency distributions for $\mathrm{PM}_{1}$ (c) and $\mathrm{PM}_{10}$ (d) size fractions.

parameter $\gamma$ in $\mathrm{PM}_{10}$ had a mean value of 1.9 and 0.5 , respectively. Two distinct sectors were identified according to wind speed and direction. For the marine sector (wind speed above $5 \mathrm{~m} \mathrm{~s}^{-1}$ and wind direction between 0 and $180^{\circ}$ ), the $\gamma$ parameter had a mean value of $0.7 \pm 0.1$ for $\gamma_{>65 \%}$, which was considerably higher than for $\gamma<65 \%$. The sharp increase in $f(\mathrm{RH})$ at an $\mathrm{RH}$ above $65 \%$ indicated the aerosol deliquescence. The anthropogenically influenced sector (wind speed above $5 \mathrm{~m} \mathrm{~s}^{-1}$ and wind direction between 225 and $315^{\circ}$ ) was characterized by a predominance of smaller and darker aerosols with lower hygroscopicity. The enhanced fine mode hygroscopic growth was more pronounced for sea salt aerosol than for mixed or anthropogenic aerosol. The airmass trajectory classification analysis agreed with the wind sector analysis. Small differences were found between clusters, with the exception of cluster 5 that corresponds to clean marine air masses.

A clear relationship between the intensive parameters SSA and SAE with $\gamma$ was observed. The $\gamma$ parameter increased for increasing SSA and decreasing SAE values, that is, larger and less absorbing particles tended to be more hygroscopic. An exponential equation which fit $\gamma$ to a single parameter (the single scattering albedo) was found to have a relatively low residual error, suggesting that SSA was a good proxy of the aerosol scattering hygroscopic growth. The Cape Cod study represents aerosol from a northern Atlantic coastal site with influence of marine and anthropogenic aerosols. The same analysis needs to be applied to other regions and aerosol types to catalog exponential fit parameters of $\gamma$ vs. SSA over a variety of aerosol types and atmospheric conditions. This particular study had a strong covariance between SSA and SAE, which allowed a reduction in the $\gamma$ fit to a single parameter, SSA. Other sites with smoke, dust or with strong differences in aerosol composition between the fine and coarse mode may require more fit parameters.

Acknowledgements. This research was funded by the NOAA Climate Program using measurements funded by the US Department of Energy Atmospheric System Research program. The authors would like to express their gratitude to the NOAA Air Resources Laboratory (ARL) for the provision of the HYSPLIT transport and dispersion model. We would like to thank also the Openair project. G. Titos was funded by the Spanish Ministry of Economy and Competitiveness - Secretariat of Science, Innovation and Development under grants BES-2011-043721 and EEBB-I-1306456, and projects P10-RNM-6299, CGL2010-18782 and EU INFRA-2010-1.1.16-262254.

Edited by: A. Carlton 


\section{References}

Anderson, T. L. and Ogren, J. A.: Determining aerosol radiative properties using the TSI 3563 integrating nephelometer, Aerosol Sci. Tech., 29, 57-69, 1998.

Bergin, M. H., Ogren, J. A., Schwartz, S. E., and McInnes, L. M.: Evaporation of ammonium nitrate aerosol in a heated nephelometer: Implications for field measurements, Environ. Sci. Technol., 31, 2878-2883, 1997.

Bond, T. C., Anderson, T. L., and Campbell, D.: Calibration and intercomparison of filter-based measurements of visible light absorption by aerosols, Aerosol Sci. Tech., 30, 582-600, 1999.

Carrico, C. M., Rood, M. J., and Ogren, J. A.: Aerosol light scattering properties at Cape Grim, Tasmania, during the First Aerosol Characterization Experiment (ACE 1), J. Geophys. Res., 103, 16565-16574, 1998.

Carrico, C. M., Rood, M. J., Ogren, J. A., Neusüb, C., Wiedensohler, A., and Heintzenberg, J.: Aerosol optical properties at Sagres, Portugal during ACE-2, Tellus, 52, 694-715, 2000.

Carrico, C. M., Kus, P., Rood, M. J., Quinn, P. K., and Bates, T. S.: Mixtures of pollution, dust, sea salt, and volcanic aerosol during ACE-Asia: Radiative properties as a function of relative humidity, J. Geophys. Res., 108, 8650, doi:doi:10.1029/2003JD003405, 2003.

Carslaw, D. C. and Ropkins, K.: Openair- An R package for air quality data analysis, Environ. Model. Softw., 27-28, 52-61, 2012.

Clarke, A. D., Howell, S., Quinn, P. K., Bates, T. S., Ogren J. A., Andrews, E., Jefferson, A., Massling, A., Mayol-Bracero, O., Maring, H., Savoie, D., and Cass, G.: INDOEX aerosol: A comparison and summary of chemical, microphysical, and optical properties observed from land, ship, and aircraft, J. Geophys. Res., 107, 8033, doi:10.1029/2001JD000572, 2002.

Covert, D. S., Charlson, R. J., and Ahlquist, N. C.: A study of the relationship of chemical composition and humidity to light scattering by aerosols, J. Appl. Meteorol., 11, 968-976, 1972.

Delene, D. J. and Ogren, J. A.: Variability of Aerosol Optical Properties at Four North American Surface Monitoring Sites, J. Atmos. Sci., 59, 1135-1149, 2002.

Draxler, R. R., Stunder, B., Rolph, G., and Taylor, A.: HYSPLIT4 User's Guide, NOAA Air Resources Laboratory, 2009.

Esteve, A. R., Ogren, J. A., Sheridan, P. J., Andrews, E., Holben, B. N., and Utrillas, M. P.: Sources of discrepancy between aerosol optical depth obtained from AERONET and in-situ aircraft profiles, Atmos. Chem. Phys., 12, 2987-3003, doi:10.5194/acp-122987-2012, 2012.

Fan, X., Chen, H., Xia, X., Li, Z., and Cribb, M.: Aerosol optical properties from the Atmospheric Radiation Measurement Mobile Facility at Shouxian, China, J. Geophys. Res., 115, D00K33, doi:10.1029/2010JD014650, 2010.

Fierz-Schmidhauser, R., Zieger, P., Wehrle, G., Jefferson, A., Ogren, J. A., Baltensperger, U., and Weingartner, E.: Measurement of relative humidity dependent light scattering of aerosols, Atmos. Meas. Tech., 3, 39-50, doi:10.5194/amt-3-392010, 2010a.

Fierz-Schmidhauser, R., Zieger, P., Gysel, M., Kammermann, L., DeCarlo, P. F., Baltensperger, U., and Weingartner, E.: Measured and predicted aerosol light scattering enhancement factors at the high alpine site Jungfraujoch, Atmos. Chem. Phys., 10, 23192333, doi:10.5194/acp-10-2319-2010, 2010 b.
Fierz-Schmidhauser, R., Zieger, P., Vaishya, A., Monahan, C., Bialek, J., O’Dowd, C. D., Jennings, S. G., Baltensperger, U., and Weingartner, E.: Light scattering enhancement factors in the marine boundary layer (Mace Head, Ireland), J. Geophys. Res., 115, D20204, doi:10.1029/2009JD013755, 2010c.

Garland, R. M., Ravishankara, A. R., Lovejoy, E. R., Tolbert, M. A., and Baynard, T.: Parameterization for the relative humidity dependence of light extinction: Organic- ammonium sulfate aerosol, J. Geophys. Res., 112, D19303, doi:10.1029/2006JD008179, 2007.

Gassó, S., Hegg, D. A., Covert, D. S., Collins, D., Noone, K. J., Öström, E., Schmid, B., Russell, P. B., Livingston, J. M., Durkee, P. A., and Jonsson, H.: Influence of humidity on the aerosol scattering coefficient and its effect on the upwelling radiance during ACE-2, Tellus, 52, 546-567, 2000.

Hänel, G. and Zankl, B.: Aerosol size and relative humidity: Water uptake by mixtures of salts, Tellus, 31, 478-486, 1979.

Hegg, D. A., Covert, D. S., Rood, M. J., and Hobbs, P. V.: Measurements of aerosol optical properties in marine air, J. Geophys. Res., 101, 12893-12903, 1996.

Heintzenberg, J., Wiedensohler, A., Tuch, T. M., Covert, D. S., Sheridan, P., Ogren, J. A., Gras, J., Nessler, R., Kleefeld, C., Kalivitis, N., Aaltonen, V., Wilhelm, R. T., and Havlicek, M.: Intercomparisons and aerosol calibrations of 12 commercial integrating nephelometers of three manufacturers, J. Atmos. Ocean. Tech., 23, 902-914, 2006.

Jefferson, A.: Aerosol Observing System (AOS) Handbook, U. S. Department of Energy, DOE/SC- ARM/TR-014, available at http://www.arm.gov/publications/tech_reports/handbooks/aos_ handbook.pdf (last access: January 2014), 2011.

Kassianov, E., Barnard, J., Pekour, M., Berg, L. K., Fast, J., Michalsky, J., Lantz, K., and Hodges, G.: Temporal variability of aerosol properties during TCAP: Impact on radiative forcing, Proc. SPIE, 8890, doi:10.1117/12.2029355, 2013.

Koloutsou-Vakakis, S., Carrico, C. M., Kus, P., Rood, M. J., Li, Z., Shrestha, R., Ogren, J. A., Chow, J. C., and Watson, G.: Aerosol properties at a midlatitude Northern Hemisphere continental site, J. Geophys. Res., 106, 3019-3032, 2001.

Kotchenruther, R. A., Hobbs, P. V., and Hegg, D. A.: Humidification factors for atmospheric aerosols off the mid-Atlantic coast of the United States, J. Geophys. Res., 104, 2239-2251, 1999.

Li-Jones, X., Maring, H. B., and Propero, J. M.: Effect of relative humidity on light scattering by mineral dust aerosol as measured in the marine boundary layer over the tropical Atlantic Ocean, J. Geophys. Res., 103, 31113-31121, 1998.

Mather, J. H. and Voyles, J. W.: The Arm Climate Research Facility: A Review of Structure and Capabilities, B. Am. Meteorol. Soc., 94, 377-392, doi:10.1175/BAMS-D-11-00218.1, 2013.

McInnes, L., Bergin, M., Ogren, J. A., and Schwartz, S.: Apportionment of light scattering and hygroscopic growth to aerosol composition, Geophys. Res. Lett., 25, 513-516, 1998.

Miller, M. A. and Slingo, A.: The ARM Mobile Facility and its first international deployment: Measuring Radiative Flux Divergence in West Africa, B. Am. Meteorol. Soc., 88, 1299-1244, doi:10.1175/BAMS-88-8-1229, 2007.

Ogren, J. A.: Comment on "Calibration and Intercomparison of Filter-Based Measurements of Visible Light Absorption by Aerosols", Aerosol Sci. Tech., 44, 589-591, 2010. 
Pan, X. L., Yan, P., Tang, J., Ma, J. Z., Wang, Z. F., Gbaguidi, A., and Sun, Y. L.: Observational study of influence of aerosol hygroscopic growth on scattering coefficient over rural area near Beijing mega-city, Atmos. Chem. Phys., 9, 7519-7530, doi:10.5194/acp-9-7519-2009, 2009.

Quinn, P. K., Bates, T. S., Baynard, T., Clarke, A. D., Onasch, T. B., Wang, W., Rood, M. J., Andrews, E., Allan, J., Carrico, C. M., Coffman, D., and Wornsnop, D.: Impact of particulate organic matter on the relative humidity dependence of light scattering: A simplified parameterization, Geophys. Res. Lett., 32, L22809, doi:10.1029/2005GL024322, 2005.

Sheridan, P. J., Delene, D. J., and Ogren, J. A.: Four years of continuous surface aerosol measurements from the Department of Energy's Atmospheric Radiation Measurement Program Southern Great Plains Cloud and Radiation Testbed site, J. Geophys. Res., 106, 20735-20747, 2001.

Sheridan, P. J., Jefferson, A., and Ogren, J. A.: Spatial variability of submicrometer aerosol radiative properties over the Indian Ocean during INDOEX, J. Geophys. Res., 107, 8011, doi:10.1029/2000JD000166, 2002.

Shinozuka, Y., Johnson, R. R., Flynn, C. J., Russell, P. B., Schmid, B., Redemann, J., Dunagan, S. E., Kluzek, C. D., Hubbe, J. M., Segal-Rosenheimer, M., Livingston, J. M., Eck, T. F., Wagener, R., Gregory, L., Chand, D., Berg, L. K., Rogers, R. R., Ferrare, R. A., Hair, J. W., Hostetler, C. A., and Burton, S. P.: Hyperspectral aerosol optical depths from TCAP flights, J. Geophys. Res.Atmos., 118, 12180-12194, doi:10.1002/2013JD020596, 2013.

ten Brink, H. M., Khlystov, A., Kos, G. P. A., Tuch, T., Roth, C., and Kreyling, W.: A high flow humidograph for testing the water uptake by ambient aerosol. Atmos. Environ., 34, 4291-4300, 2000 .

Wang, J. and Martin, S. T.: Satellite characterization of urban aerosols: Importance of including hygroscopicity and mixing state in the retrieval algorithms, J. Geophys. Res., 112, D17203, doi:10.1029/2006JD008078, 2007.
WMO/GAW: Aerosol measurement procedures guidelines and recommendations, GAWRep. 153, World Meteorol. Organ., Geneva, Switzerland, available at ftp://ftp.wmo.int/Documents/ PublicWeb/arep/gaw/gaw153.pdf (last access: July 2014), 2003.

Yan, P., Pan, X., Tang, J., Zhou, X., Zhang, R., and Zeng, L.: Hygroscopic growth of aerosol scattering coefficient: A comparative analysis between urban and suburban sites at winter in Beijing, Particuology, 7, 52-60, 2009.

Zieger, P., Fierz-Schmidhauser, R., Gysel, M., Ström, J., Henne, S., Yttri, K. E., Baltensperger, U., and Weingartner, E.: Effects of relative humidity on aerosol light scattering in the Arctic, Atmos. Chem. Phys., 10, 3875-3890, doi:10.5194/acp-10-38752010, 2010.

Zieger, P., Weingartner, E., Henzing, J., Moerman, M., de Leeuw, G., Mikkilä, J., Ehn, M., Petäjä, T., Clémer, K., van Roozendael, M., Yilmaz, S., Frieß, U., Irie, H., Wagner, T., Shaiganfar, R., Beirle, S., Apituley, A., Wilson, K., and Baltensperger, U.: Comparison of ambient aerosol extinction coefficients obtained from in-situ, MAX-DOAS and LIDAR measurements at Cabauw, Atmos. Chem. Phys., 11, 2603-2624, doi:10.5194/acp11-2603-2011, 2011.

Zieger, P., Kienast-Sjögren, E., Starace, M., von Bismarck, J., Bukowiecki, N., Baltensperger, U., Wienhold, F. G., Peter, T., Ruhtz, T., Collaud Coen, M., Vuilleumier, L., Maier, O., Emili, E., Popp, C., and Weingartner, E.: Spatial variation of aerosol optical properties around the high-alpine site Jungfraujoch (3580 m a.s.1.), Atmos. Chem. Phys., 12, 72317249, doi:10.5194/acp-12-7231-2012, 2012.

Zieger, P., Fierz-Schmidhauser, R., Weingartner, E., and Baltensperger, U.: Effects of relative humidity on aerosol light scattering: results from different European sites, Atmos. Chem. Phys., 13, 10609-10631, doi:10.5194/acp-13-10609-2013, 2013. 